\title{
Hubungan Lebar Karapas dan Berat Rajungan Portunus pelagicus, Linnaeus, 1758 (Malacostraca : Portunidae) di Perairan Sambiroto Pati, Jawa Tengah
}

\author{
Rindika Wahyu*, Nur Taufiq-SPJ, Sri Redjeki \\ Departemen IImu Kelautan, Fakultas Perikanan dan IImu Kelautan, Universitas Diponegoro \\ JI. Prof H.Soedharto S H, Tembalang, Semarang, Jawa Tengah 50275 Indonesia \\ ${ }^{*}$ Corresponding author, e-mail : rindikawe@gmail.com
}

\begin{abstract}
ABSTRAK : Rajungan (Portunus pelagicus) merupakan salah satu produk perikanan yang memiliki nilai ekonomi tinggi. Tujuan dalam penelitian ini yaitu untuk mengetahui variasi panjang, lebar dan berat rajungan (Portunus pelagicus) di Perairan Sambiroto pati dan Mengetahui rasio jantan betina rajungan yang tertangkap di Perairan Sambiroto Pati. Penelitian ini dilaksanakan pada bulan Oktober-November 2018 di Perairan Sambiroto, Pati. Pengambilan data rajungan meliputi data lebar dan berat rajungan. Hasil penelitian ini menunjukkan 744 ekor rajungan yang diamati diketahui variasi ukuran rajungan yang tertangkap baik jantan dan betina yang berukuran lebar > $120 \mathrm{~mm}$ sebanyak $68,52 \%$ dari jumlah seluruhnya yang tertangkap. Rajungan yang tertangkap di Sambiroto memiliki pertumbuhan yang bersifat allometrik negatif dengan nilai $b$ sebesar 2,21 pada rajungan jantan dan 1,17 pada rajungan betina. Sehingga diketahui pertumbuhan lebar lebih cepat daripada pertumbuhan berat rajungan
\end{abstract}

Kata Kunci : Portunus pelagicus; Berat; Lebar Karapas

\section{Morfometry of Portunus pelagicus, Linnaeus, 1758 (Malacostraca : Portunidae) in Sambiroto Pati, Jawa Tengah}

ABSTRACT : Swimming crab (Portunus pelagicus) is a fishery product that has high economic value. The purpose of this study is to determine the variation in length, width and weight of crabs (Portunus pelagicus) in Sambiroto starch waters and to determine the ratio of crab females that are caught in Sambiroto Pati waters. This research was conducted in October-November 2018 in Sambiroto Waters, Pati. The crab retrieval data includes the crab width and weight data. The results of this study showed that 744 small crabs observed sizes variations of small crab caught both males and females with width> $120 \mathrm{~mm}$ totaling $68.52 \%$ of the total number caught. The crabs caught in Sambiroto have negative allometric growth with a b value of 2.21 in male crabs and 1.17 in female crabs. So it is known that the width growth is faster than the crab weight growth.

Keywords: blue swimming crab; Weight; carapace widht

\section{PENDAHULUAN}

Rajungan (Portunus pelagicus) merupakan salah satu famili kepiting yang banyak diperdagangkan. Rajungan merupakan salah satu komponen perikanan bernilai tinggi di banyak negara terutama di daerah tropis (Chande and Mgaya, 2003). Rajungan dicirikan dengan karapas yang relatif lebih panjang dan memiliki duri cangkang yang lebih panjang dibandingkan dengan kepiting bakau (Juwana, 1997). Permintaan pasar daging rajungan terus meningkat terutama untuk kebutuhan ekspor. Cangkang kering rajungan juga dapat dimanfaatkan menjadi produk industri berupa kitosan yang sangat dibutuhkan pada bidang kesehatan, farmasi dan mikrobiologi. Rajungan di alam ditangkap dengan menggunakan alat tangkap arad, gill net dan bubu lipat. Permintaan pasar yang meningkat, maka mendorong penangkapan rajungan semakin meningkat.

Distribusi geografis rajungan ditemukan membentang dari laut Mediterania selatan sampai pantai timur Afrika. Rajungan juga tersebar sepanjang pinggir pantai perairan tropis dam bagian barat Samudera Hindia sampai bagian timur Samudera Pasifik (Chande and Mgaya, 2003). Pada dasarnya, Rajungan hidup di berbagai habitat seperti pantai dengan dasar pasir, pasir lumpur, perairan dangkal dengan kedalaman antara 1 sampai 4 meter dan tersebar hingga kedalaman 
mencapai 50 meter serta sesekali ia berdiam diri pada kedalaman $65 \mathrm{~m}$ (Prasetyo et al., 2014), kemudian berenang ke permukaan laut, daerah berpasir untuk bernafas dan melihat organisme lain atau mangsanya dengan mata yang tajam dan menjulurkan antenanya (Lakudo et al., 2017). Permintaan pasar yang meningkat hampir menjadikan rajungan sebagai biota ekspor dengan nilai yang tinggi (Yusfianda dan Sobari, 2011).

Distribusi rajungan yang tidak menentu tersebut juga berpengaruh langsung terhadap jumlah hasil tangkapan nelayan rajungan setiap bulannya. Berdasarkan hal tersebut, perlu dilakukan kajian distribusi rajungan sehingga diperoleh informasi yang dapat digunakan untuk mengoptimalkan hasil tangkapan rajungan. Tingkat pemanfaatan rajungan yang tinggi akan berpengaruh pada status stok di perairan, terlebih jika yang ditangkap adalah rajungan muda, karena dapat menghambat laju penambahan stok baru (Zairion et al., 2015). Perlu adanya informasi mengenai ukuran dan kondisi rajungan yang ada di Sambiroto sebagai pemantau kondisi populasi rajungan sekarang. Kementrian Kelautan dan Perikanan Republik Indonesia No. 01/PERMEN-KP/2015, tanggal 6 januari 2015, mengatur tentang ukuran tangkap rajungan (Portunus pelagicus) diperbolehkan hanya pada ukuran lebar karapas di atas $10 \mathrm{~cm}$ dan rajungan tidak sedang bertelur. Kegiatan penangkapan rajungan yang demikian tersebut diharapkan dapat memberikan keberlanjutan sumberdaya rajungan. Berdasarkan uraian tersebut, maka permasalahan yang ingin disampaikan dalam penelitian ini adalah bagaimana kondisi morfometri rajungan (Portunus pelagicus) yang ada di Perairan Sambiroto, Pati.

Penelitian ini bertujuan untuk mengetahui Mengetahui variasi panjang, lebar dan berat rajungan (Portunus pelagicus) di Perairan Sambiroto Pati. Mengetahui rasio jantan betina rajungan yang tertangkap di Perairan Sambiroto Pati.

\section{MATERI DAN METODE}

Penelitian dilakukan di Perairan Sambiroto Pati. Metode yang digunakan dalam penelitian ini adalah metode penelitian deskriptif. Materi penelitian meliputi pengambilan sampel rajungan dan pengukuran lebar karapas dan berat rajungan. Pengambilan data dengan cara mengumpulkan semua rajungan yang didapat oleh nelayan rajungan. Lebar karapas rajungan diukur dengan menggunakan jangka sorong atau kalier (dengan ketelitian 0,05). Berat tubuh rajungan ditimbang dengan menggunakan timbangan digital (dengan ketelitian 0,1 gram). Lebar rajungan diukur dari duri lateral terpanjang yang berada disisi-sisi tubuhnya.

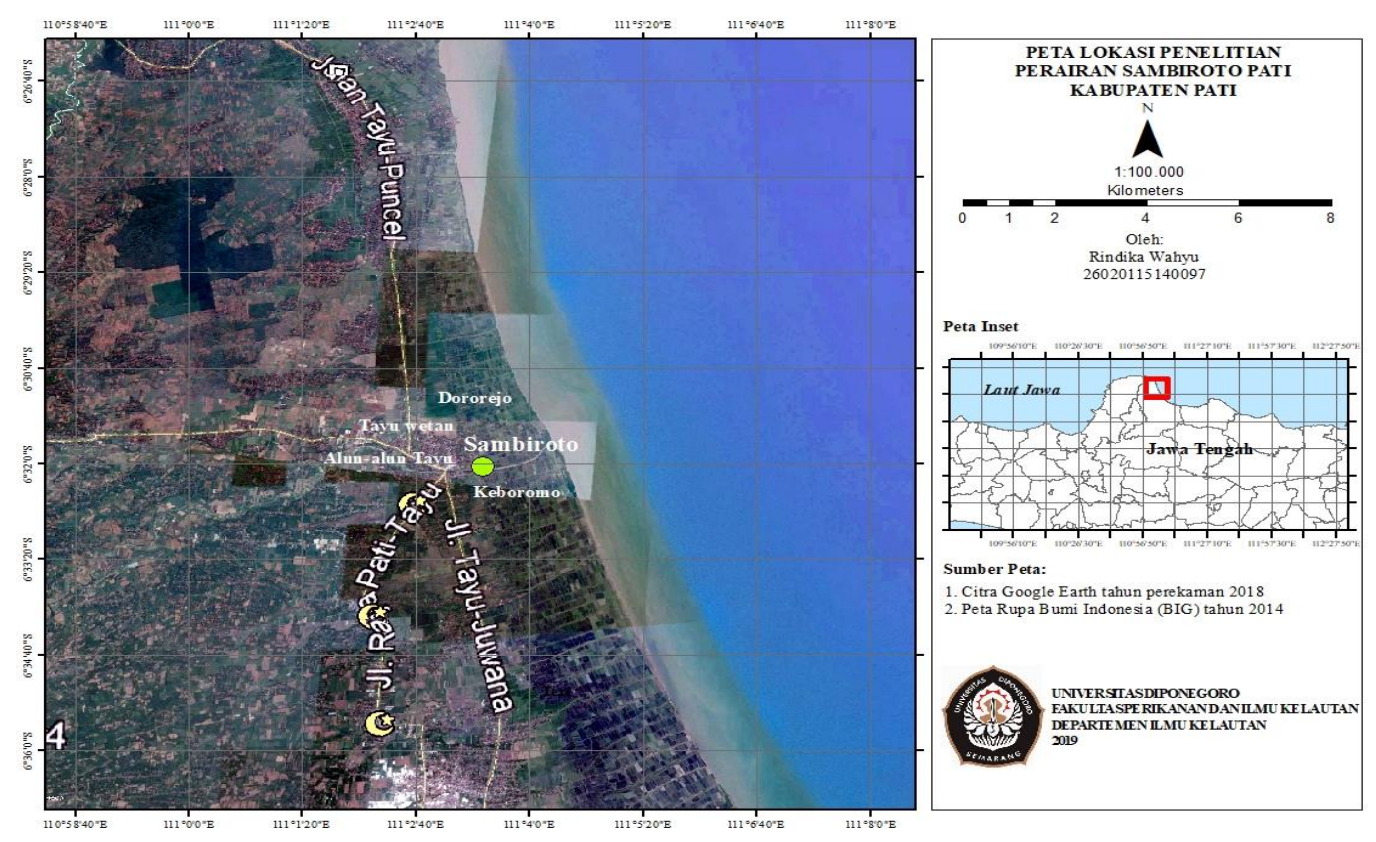

Gambar 1. Peta Lokasi Penelitian di Desa Sambiroto 
Distribusi lebar karapas dan berat rajungan dianalisa degan menggunaan Software Microssoft Excel, dengan menginput data lebar karapas dan berat rajungan, didalam grafik distribusi. Langkah yang dilakukan dalam penentuan distribusi frekuensi ukuran lebar karapas dan berat tubuh rajungan adalah menentukan nilai maksimum dan minimum dari keseluruhan data lebar karapas dan berat kepiting yang didapat dari jumlah total Portunus pelagicus; menentukan lebar dan berat dari interval kelas; menentukan kelas frekuensi dan memasukan frekuensi masingmasing kelas dengan memasukan lebar dan berat tubuh dari masing-masing contoh rajungan pada interval kelas yang ditentukan.

Rajungan yang tertangkap pada setiap pengambilan contoh dipisahkan berdasarkan jenis kelamin, kemudian jumlah rajungan jantan dan betina dihitung dan dicatat. Rasio kelamin rajungan ditentukan berdasarkan rasio jumlah rajungan jantan terhadap jumlah rajungan betina yang tertangkap selama penelitian berlangsung (Lawson dan Oloko 2013) :

$$
\text { Rasio Kelamin }=\frac{\sum \text { Jantan }}{\sum \text { Betina }}
$$

Kangas (2000) menyatakan hubungan antara lebar dan berat tubuh diformulasikan :

$$
\mathbf{W}=\mathbf{a L}^{\mathbf{b}}
$$

Keterangan : $\mathrm{W}=$ Berat rajungan (gram); $\mathrm{L}=$ Lebar karapas $(\mathrm{mm}) ; \mathrm{A}=$ Intersep (perpotongan kurva); $b=$ penduga pola pertumbuhan lebar karapas-berat

\section{HASIL DAN PEMBAHASAN}

Rajungan yang diukur memiliki kisaran ukuran lebar karapas 70 - $179 \mathrm{~mm}$ dan kisaran berat sebesar 40 - 299 gram. Berdasarkan hasil analisa Tabel 1 modus ukuran lebar karapas rajungan jantan terdapat pada interval kelas lebar $120 \mathrm{~mm}$ sedangkan modus ukuran lebar karapas rajungan betina terdapat pada interval pada interval lebar $120 \mathrm{~mm}$. Modus ukuran berat rajungan jantan terdapat pada interval berat 140 gram sedangkan modus ukuran berat rajungan betina terdapat pada interval berat 110 gram. Dalam penelitian Arios et al., (2013) menyatakan rajungan jantan dan betina di Perairan Teluk Awur memiliki puncak frekuensi pada berat 81 - 110 gram. Hasil ini lebih kecil jika dibandingkan dengan daerah Rembang yang mempunyai puncak frekuensi pada berat 161,5 - 187,9 gram. Sampel rajungan yang diamati dan diukur selama penelitian berjumlah sebanyak 744 ekor terdiri dari 391 ekor rajungan jantan dan 353 ekor rajungan betina. Jumlah rajungan jantan selama penelitian lebih banyak dibandingkan rajungan betina tetapi untuk rasio perbandingannya $1,1: 1$.

Hal ini dikarenakan terjadi cuaca buruk dan gelombang tinggi sehingga hanya sedikit nelayan yang tetap melakukan aktivitas penangkapan di lokasi penelitian. Pengambilan sampel yang dilakukan pada musim penghujan berdampak pada minimnya kuantitas tangkapan nelayan. Menurut Dineshbabu et al., (2007), kemungkinan rajungan akan bermigrasi ke perairan yang dalam selama musim penghujan berlangsung. Untuk meningkatkan kuantitas tangkapan pada saat musim penghujan, nelayan harus mencari fishing ground pada perairan yang dalam didekat pantai. Pada musim memijah, yakni pada Bulan Desember, Maret, Juli dan September, rajungan betina akan berimigrasi ke perairan yang memiliki salinitas yang lebih tinggi. Sehingga pada musim memijah daerah laut lepas didominasi oleh rajungan betina. Perbandingan rajungan jantan dan betina yang tidak seimbang perlu diperhatikan. Tingginya rajungan betina yang tangkap berakibat buruk pada kelestarian rajungan, karena dapat mengurangi/menghambat proses rekrutmen stok di daerah tersebut. Tirtadanu et al., (2017) menyatakan bahwa proses penambahan populasi bisa terhambat disebabkan menurunnya populasi rajungan betina. Sumpton et al., (1994) menyatakan bahwa rajungan betina cenderung memilih substrat yang berpasir selama musim pemijahan sehingga rajungan betina pergi ke daerah yang berpasir, hal ini menyebabkan hasil tangkapan cenderung jantan. 


\section{Hubungan Lebar Karapas dan Berat Portunus pelagicus}

Berdasarkan hasil analisa, sifat pertumbuhan rajungan pada keseluruhan rajungan baik jantan maupun betina, di perairan Sambiroto Pati selama penelitian bersifat allometrik negatif dengan nilai b sebesar 2,01 untuk rajungan jantan dan 1,17 untuk rajungan betina (Tabel 2). hasil yang berlainan tersebut menunjukan bahwa hubungan lebar karapas dan bobot rajungan berrsifat dinamis pada kondisi perairan yang berbeda. Nilai $b$ pada rajungan jantan lebih besar dibandingkan pada rajungan betina, menunjukkan bahwa pada ukuran yang sama rajungan jantan memiliki berat lebih besar dibandingkan betina. Hal ini dapat terjadi karena rajungan betina dalam kondisi pre-moult, pada fase pematangan gonad dan mengerami telur yang memiliki kebiasaan makan sedikit atau berenti makan sehingga bobot rajungan menjadi tidak proporsional dengan lebar karapasnya (Josileen, 2011).

Perbedaan pada hubungan lebar karapas-bobot tubuh sering terjadi bergantung pada banyaknya faktor lingkungan yang mempengaruhi seperti suhu, salinitas, makanan (kuantitas dan kualitas), jenis kelamin dan tahap kematangan gonad. Perbedaan pola pertumbuhan di antara spesies juga dapat terjadi akibat variasi pengaruh penangkapan dan/atau akibat perbedaan faktorfaktor abiotik seperti salinitas, pH, curah hujan, DO dan khususnya suhu. Selain itu, Araujo \& Lira (2012) juga menyatakan bahwa tidak ada pola pertumbuhan yang tetap pada famili Portunidae.Dari hasil perhitungan nilai faktor kondisi, diketahui bahwa nilai faktor kondisi rata-rata rajungan jantan lebih tinggi dibandingkan rajungan betina. Hasil ini berbeda dengan hasil-hasil pada umumnya yang menyatakan bahwa nilai faktor kondisi rajungan betina justru lebih tinggi dibandingkan rajungan jantan (Damora dan Nurdin 2016).

Tabel 1. Jumlah Individu, Nilai Kisaran Lebar Karapas serta Berat Rajungan Jantan-Betina Selama Penelitian.

\begin{tabular}{llll}
\hline Indikator & Jantan & Betina & Rajungan Total \\
\hline Mean & Lebar Karapas $(\mathrm{mm})$ & & \\
Modus & 120,08 & 118,47 & 119,31 \\
Median Lebar & 120 & 120 & 120 \\
Standar Deviasi & 16,01 & & 120 \\
Lebar Minimal & 70 & 16,15 & 16,09 \\
Lebar Maksimal & 171 & 75 & 70 \\
Jumlah ukuran $<=$ & 30 & 154 & 171 \\
100mm & & 42 & \\
Jumlah ukuran $>=$ & 361 & 311 & \\
100mm & Jantan & Betina & Rajungan Total \\
Indikator & & & \\
\hline & 138,69 & 123,65 & 131,55 \\
Mean & 140 & 110 & 140 \\
Modus & 54,36 & 47,03 & 51,53 \\
Standar Deviasi & 290 & 281 & 290 \\
Berat Maksimal & 41 & 47 & 41 \\
Berat Minimal & & & 120 \\
Median & 391 & 353 & 744 \\
\hline Total & & &
\end{tabular}


Hasil ini bisa terjadi akibat sedikit perbedaan pada nilai koefisien regresi di antara jenis kelamin. Dimorfisme dalam laju metabolisme, aspek nutrisi, tahap kematangan gonad dan waktu rekruitmen mungkin juga dapat mempengaruhi perbedaan nilai faktor kondisi pada masing-masing jenis kelamin. Pola fluktuasi nilai faktor kondisi yang serupa antara jantan dan betina menunjukkan adanya sinkronisasi hubungan proses reproduksi rajungan (Araujo dan Lira 2012).

Berdasarkan hasil penelitian secara keseluruhan rasio perbandingan jumlah rajungan jantan dan betina yang tertangkap selama penelitian adalah sebesar 1:1. Sebagai pembanding, pada penelitian sebelumnya rasio kelamin jantan dan betina rajungan di perairan Betahwalang adalah 1:1,1 (Ningrum, 2015). Berbedanya perbandingan sex rasio antara jumlah rajungan jantan dan betina yang tertangkap oleh nelayan kemungkinan dikarenakan adanya perubahan perilaku dari masing-masing individu dalam mencari habitat yang sesuai, pengaruh dari penangkapan, mortalitas dan rekruitmen. Pada musim penghujan saat suhu perairan turun rajungan akan berada pada kondisi tidak aktif, rajungan akan banyak menghabiskan waktu mengubur diri dalam pasir untuk menjaga suhu tubuh agar tetap stabil (Kangas, 2000) dan kemungkinan rajungan akan bermigrasi ke perairan yang lebih dalam (Dineshbabu et al., 2007).

Migrasi yang dilakukan oleh rajungan betina yang matang gonad dalam mencari habitat yang sesuai menuju perairan yang bersalinitas tinggi ini juga dapat menyebabkan variasi dalam perbandingan sex rasio antara jantan dan betina yang tertangkap pada musim pemijahan. Sex rasio juga dapat dijadikan parameter kelimpahan satu spesies pada suatu lokasi penangkapan. Sebagai contoh Kangas (2000) mendapatkan perbandingan sex rasio yang seimbang (1:1) pada daerah estuaria. Artinya pada lokasi tersebut terjadi rekruitmen anggota baru yang seimbang dari proses penetasan telur sehingga proporsi jumlah rajungan jantan dan betina yang tertangkap seimbang.

Tabel 2. Hubungan Lebar Karapas dan Berat Portunus

\begin{tabular}{ccccccc}
\hline Jenis & \multicolumn{5}{c}{ Parameter Hubungan Lebar Karapas dan Berat Rajungan } \\
\cline { 2 - 7 } Kelamin & $\mathrm{N}$ & $\mathrm{a}$ & $\mathrm{b}$ & $\mathrm{r}$ & $\mathrm{R}^{2}$ & Sifat Pertumbuhan \\
\hline Jantan & 391 & 0,0032 & 2,21 & 0,74 & 0,55 & Allometrik Negatif \\
\hline Betina & 353 & 0,0235 & 1,17 & 0,67 & 0,46 & Allometrik Negatif \\
\hline Total & 744 & 0,008 & 2,01 & 0,71 & 0,50 & Allometrik Negatif \\
\hline
\end{tabular}

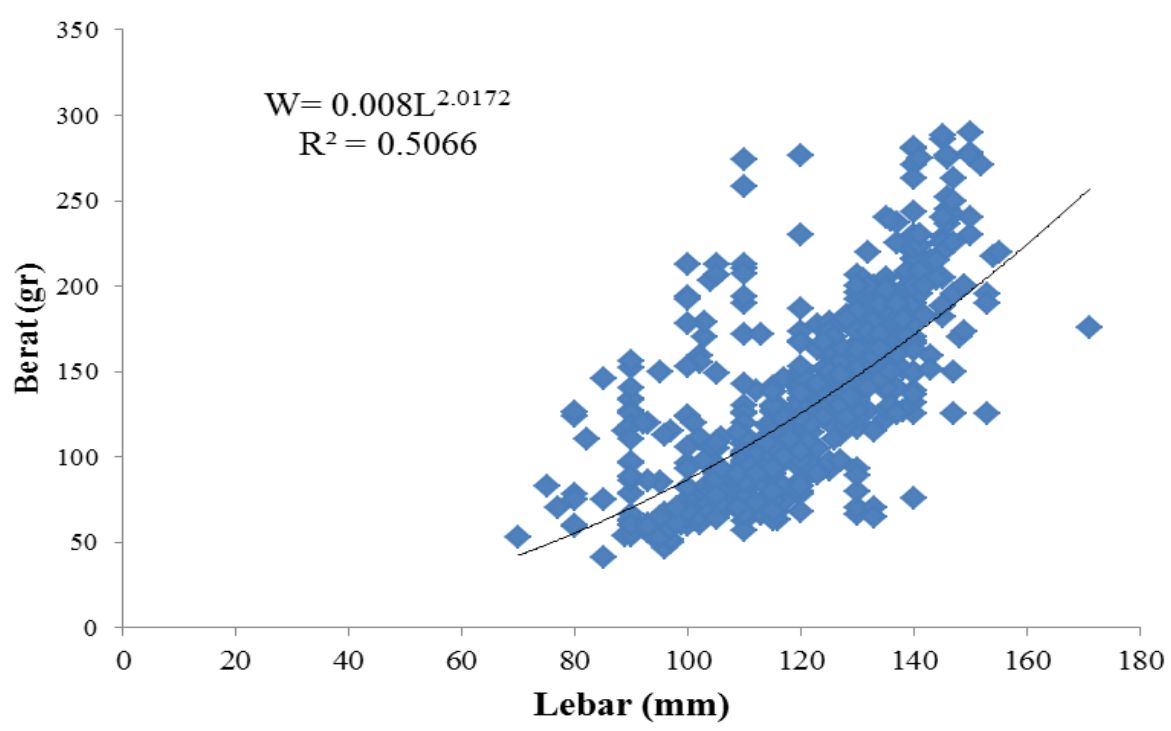

Gambar 2. Hubungan Lebar Karapas - Berat Portunus pelagicus Total Hasil Tangkapan Selama Penelitian di Kawasan Perairan Sambiroto, Pati. 


\section{KESIMPULAN}

Sebaran ukuran lebar rajungan yang tertangkap baik jantan dan betina yang berukuran lebar $>120 \mathrm{~mm}$ sebanyak $68,52 \%$ dari jumlah seluruhnya yang tertangkap. Pola pertumbuhan rajungan (Portunus pelagicus) jantan dan betina yang tertangkap di perairan Sambiroto adalah allometrik negatif dengan nilai b sebesar 2,2182 pada rajungan jantan dan 1,1783 pada rajungan betina.

\section{UCAPAN TERIMA KASIH}

Artikel ini merupakan bagian dari skripsi yang berjudul "Morfometri Rajungan (Portunus pelagicus, Linnaeus, 1758 (Malacostraca : Portunidae)) di Perairan Sambiroto Pati, Jawa Tengah", untuk memperoleh gelar Sarjana Strata Satu Program Studi IImu Kelautan, Fakultas Perikanan dan IImu Kelautan Universitas Diponegoro.

\section{DAFTAR PUSTAKA}

Araujo, M.S.L.C, \& Lira, J.J.P.R. 2012. Condition factor and carapace width versus wet weight relationship in the swimming crab Callinectes danae Smith 1869 (Decapoda: Portunidae) at the Santa Cruz Channel, Pernambuco State, Brazil. Nauplius, 20(1):41-50.

Arios, A.H., Solichin, A. \& Saputra, S.W. 2013. Hasil Tangkapan Rajungan (Portunus pelagicus) dengan Menggunakan Alat Tangkap Bubu Lipat yang Didaratkan di TPI Tanjung Sari Kabupaten Rembang. Journal of Management of Aquatic Resources, 2(2):

Chande, A.I. \& Magya, Y.D. 2003. The Fishery of Portunus pelagicus and Speciesdiversiy of Portunid Crabs Along the Coast of Dar es Salam, Tanzania. Western Indian Ocean Journal of Marine Science, 2(1):75-84

Damora, A., \& Nurdin, E. 2016. Beberapa aspek biologi rajungan (Portunus pelagicus) di perairan Labuhan Maringgai, Lampung Timur. Bawal, 8 (1):13-20.

Dineshbabu, A.P., Sreedhara, B. \& Muniyappa, Y. 2007. Fishery and Stock Assessment of Portunus sanguinolentus (Herbst) from South Karnataka Coast, India. Journal of the Marine Biological Association of India, 49(2):134-140.

Josileen. J. 2011. Morphometrics and Length-Weight Relationship in the Blue Swimmer Crab, Portunus pelagicus (Linnaeus, 1758) (Decapoda, Brachyura) From the Madapan Coast, India. Crustasea. 84(14):1665-1681

Juwana S. 1997. Tinjauan tentang Perkembangan Penelitian Budidaya Rajungan (Portunus pelagicus). Oseana, 22(4):1-12.

Kangas, M.I. 2000. Synopsis of the Biology and Exploitation of the Blue Swimmer Crab, (Portunus pelagicus Linnaeus) in Western Australia. Fisheries Research Report. 121:1-22.

Lakudo, A.H., Wardiatno, Y., Lumban, D.T.F., \& Riani, E. 2017. Pengelolaan Rajungan (Portubbus pelagicus) yang berkelanjutan berdasarkan Aspek Bioekologi di Teluk Lasongko Sulawesi Tenggara. Jurnal Kebijakan Perikanan Indonesia, 9(1):41-50.

Lawson, E.O \& Oloko, R.T. 2013. Growth patterns, Sex ratios and Fecundity estimates in Blue Crab (Callinectes amnicola) from Yewa River, Southwest Nigeria. Advances in Life Science and Technology, 7:24-33.

Ningrum, V.P., Ghofar, A. \& Ain, C. 2015. Beberapa aspek biologi perikanan rajungan (Portunus pelagicus) di perairan Betahwalang dan sekitarnya. Indonesian Journal of Fisheries Science and Technology, 11(1): 62-71.

Prasetyo, G.D., Fitri, A.D.P. \& Yulianto, T. 2014. Analisis Daerah Penangkapan Rajungan (Portunus pelagicus) berdasarkan Perbedaan Kedalaman Perairan dengan Jaring Arad (Mini Trawl) di Perairan Demak. Journal of Fisheries Resources Utilization Management and Technology, 3(3):257-266.

Sumpton, W.D., Potter, M.A. \& Smith, G.S. 1994. Reproductions and Growth of the Commercial Sand Crab (Portunus pelagicus) in Moreton Bay Queensland. Asian Fisheries Science 7:103133. 
Tirtadanu \& Suman, A. 2017. Aspek Biologi, Dinamika Populasi dan Tingkat Pemanfaatan Rajungan (Portunus pelagicus Linnaeus, 1758) di Perairan Kotabaru, Kalimantan Selatan. Jurnal Penelitian Perikanan Indonesia, 23(3):205-214

Yusfianda, R. \& Sobari, M.P. 2017. Aspek Bioteknik dalam Pemanfaatan Sumberdaya Rajungan di Perairan Teluk Banten. Jurnal Teknologi Perikanan dan Kelautan, 2(1):71-80.

Zairion, Wardiatno, Y., Boer, M., \& Fahrudin, A. 2015. Reproductive biology of the blue swimming crab Portunus pelagicus (Brachyura: Portunidae) in East Lampung Waters, Indonesian: fecundity and reproductive potential. Tropical Life Sciences Research 26(1):67-85. 